\title{
Connexin26 gene (GJB2): prevalence of mutations in the Chinese population
}

\begin{abstract}
The connexin26 gene (GJB2) has been shown to be responsible for DFNB1 and DFNA3 (Autosomal Recessive Hereditary Nonsyndromic Deafness Locus 1 and Autosomal Dominant Hereditary Nonsyndromic Deafness Locus $3)$. Two hundred ten independently ascertained Chinese probands with nonsyndromic hearing loss (NSHL) were evaluated for mutations in $G J B 2$, including 43 probands from families with more than one sib with NSHL, likely indicating dominant inheritance, and sporadic cases of NSHL, compatible with recessive inheritance. Of the 210 probands, $43(20 \%)$ were homozygous or heterozygous for mutations in GJB2. Four different mutations were identified: 35delG, 109G-A, 235delC, and 299-300delAT. It was confirmed that GJB2 mutations are an important cause of hearing loss in this population. Of these four mutations, $235 \mathrm{delC}$ was the most prevalent at $93 \%$; yet the $35 \mathrm{delG}$ mutation, which is the most common GJB2 mutation in Caucasian subjects (Europeans and Americans), was found in low frequency in the present study. It appears from our limited data and reports from other East Asians that 235delC is the most prevalent $G J B 2$ mutation in these populations. $G J B 2$ mutations are consistent with ethnic predilections.
\end{abstract}

Key words Nonsyndromic hearing loss · GJB2 Connexin26 (Cx26) $\cdot$ Mutation $\cdot$ Chinese

\section{Introduction}

Genetic causes are believed to account for at least $60 \%$ of cases of hearing impairment. Close to 80 human loci causing nonsyndromic hearing loss (NSHL) have been mapped and 31 identified; 24 genes have been determined to cause

Y. Liu $(\bowtie) \cdot$ X. Ke

Department of Otolaryngology-Head and Neck Surgery, Peking

University First Hospital, Beijing 100034, China

Tel. +86-10-66171122; Fax +86-10-63079165

e-mail: liuyuhe@xinhuanet.com

Y. Qi · W. Li · P. Zhu

Center Laboratory, Peking University First Hospital, Beijing, China
NSHL (Van Camp and Smith 2002, http://www.iro.es/ deafness/). Prominent genes are those encoding gap junctions. Connexin26 is believed to play a critical role in the recycling of potassium ions at their entry into hair cells during sensory transduction from the endolymph through to the stria vascularis where other potassium channels pump potassium back into the endolymph (Scott et al. 1998). Connexin 26 gene (GJB2) mutations were first reported by Kelsell et al. in 1997. Mutations of GJB2, which is responsible for DFNB1 and DFNA3 (Autosomal Recessive Hereditary Nonsyndromic Deafness Locus 1 and Autosomal Dominant Hereditary Nonsyndromic Deafness Locus 3), are the most frequent cause of inherited hearing loss (Cohn et al. 1999; Denoyell et al. 1998; Fuse et al. 1999; Kelley et al. 1998). In some regions, mutations in GJB2 account for about $50 \%$ of autosomal recessive prelingual NSHL (Denoyelle et al. 1997; Estivill et al. 1998; Zelante et al. 1997).

The prevalence of NSHL is high in the Chinese population. To estimate the proportion of inherited deafness attributed to GJB2 in the Chinese population, we checked the coding DNA sequence (CDS) of GJB2 with polymerase chain reaction (PCR), single-strand conformational polymorphism (SSCP), and restriction fragment length polymorphism (RFLP) in 210 independently ascertained probands with NSHL.

\section{Subjects and methods}

All 210 independently ascertained probands with bilateral sensorineural NSHL were from different regions of China, and were 5-54 years old. Among them, 43 probands were from families with more than one sib with NSHL, likely indicating dominant inheritance; the others were sporadic cases of hearing loss, compatible with recessive inheritance. Informed consent was obtained from all participants and parents of patients younger than 18 years. Excluded from this study were individuals with acquired hearing loss (environmental causes: infection, noise, drug ototoxicity, and trauma). Evaluation included a complete case history, physi- 
cal examination, and audiometry. All individuals underwent pure-tone audiometry by diagnostic audiometer (Siemens Danplex DA 74 Clinical Diagnostic Audiometer, NJ, USA) in a soundproof room. Pure-tone averages of more than 25 dBHL (mean dBHL at 500,1000, and $2000 \mathrm{~Hz}$ ) were defined as hearing loss. The degree of hearing impairment ranged from mild to profound, and 81 probands showed no measurable hearing level. The control population consisted of 200 randomly selected normal Chinese.

DNA was isolated from peripheral-blood lymphocytes according to standard protocols. Three PCR primer pairs from the GJB2 sequence were designed to cover $681 \mathrm{bp}$ of the coding region. Amplification was performed with the following primer pairs: $1 \mathrm{~F} 5^{\prime}$-TCT TTT CCA GAG CAA ACC GC-3', 1R 5'-GAC ACG AAG ATC AGC TGC AG3'; 2F 5'-GCT GCA AGA ACG TGT GCT AC-3', 2R 5'TGG GTT TTG ATC TCC TCG AT-3'; and 3F 5'-CGA GGA GAT CAA AAC CCA GA-3', 3R 5'-GGA CAC AAA GCA GTC CAC AG-3'.

PCR was performed using $100 \mathrm{ng}$ of human DNA in a 25- $\mu$ l PCR reaction, which contained $2.5 \mu$ l PCR buffer $(100 \mathrm{mM}$ of tris-hydrochloride, $\mathrm{pH} 8.8,500 \mathrm{mM}$ of potassium chloride, $15 \mathrm{mM}$ of magnesium chloride, $0.01 \% \mathrm{wt} / \mathrm{vol}$ gelatin), $200 \mu \mathrm{M}$ mixed deoxyribonucleoside triphosphates, and $25 \mathrm{pM}$ primer. Samples were denatured at $95^{\circ} \mathrm{C}$ for $5 \mathrm{~min}$ followed by 30 cycles at $94^{\circ} \mathrm{C}$ for $40 \mathrm{~s}, 60^{\circ} \mathrm{C}$ for $30 \mathrm{~s}$, and $72^{\circ} \mathrm{C}$ for $30 \mathrm{~s}$, with a final extension for $7 \mathrm{~min}$ at $72^{\circ} \mathrm{C}$.

The PCR products were screened by SSCP for mutations in GJB2, followed by sequencing after purification (Bio-applied Corporation, Shanghai, China) if SSCP shifts were observed. After finding mutations, all samples were checked with RFLP (Table 1).

\section{Results}

Four different GJB2 mutations (three frameshift mutations and a missense mutation) were identified among 210 probands (Tables 1 and 2); 43 (20\%) carried mutations in GJB2, including 4 with and 39 without deaf sibs. Three single-nucleotide polymorphisms (SNPs), 79G-A, 257258GC-CG, and 341A-G, were detected. 79G-A and 341A$\mathrm{G}$ were reported previously, whereas one novel SNP, 257-258GC-CG (no amino acid change), was observed in all sequencing samples of 18 probands and 6 controls. Among 200 hearing controls from the general Chinese population, one individual was heterozygous for $235 \mathrm{delC}$. No control carried any other mutations.

The frameshift mutation $235 \mathrm{delC}$ was found in 40 probands, 3 in homozygotes whose parents are NSHL and homozygous, 24 in homozygotes with sporadic hearing loss, and 13 in heterozygotes with sporadic hearing loss in which no other mutation of GJB2 was detected. Three heterozygous mutations, 35delG, 109G-A, and 299-300delAT, were detected in three probands, respectively. No other mutation in GJB2 was detected. The same heterozygous mutation, 299-300delAT, was also found in the proband whose mother has NSHL. The homozygous mutations in GJB2, which were observed in $13 \%$ of all probands, accounted for $16 \%(27 / 210-43+3)$ of all autosomal recessive deafness in the tested populations. The mutation 109G-A could not be checked with RFLP because there is no appropriate restriction endonuclease site for it. The $235 \mathrm{delC}$ mutation causes a frameshift at codon 79 , resulting in a truncated polypeptide. 299-300delAT causes a frameshift leading to an altered amino acid sequence starting from codon 100 , followed by a stop at codon 113.

\section{Discussion}

Mutations in GJB2 are responsible for a substantial proportion $(13 \%)$ of hearing loss in the Chinese. Four different mutations appear in 43 probands, 27 homozygous for the same allele. The carrier frequency of these mutations in the

Table 1. Mutations checked with RFLP

\begin{tabular}{|c|c|c|c|c|c|}
\hline $\begin{array}{l}\text { GJB2 } \\
\text { mutation }\end{array}$ & $\begin{array}{l}\text { Restriction } \\
\text { endonucleases } \\
\text { (U) }\end{array}$ & $\begin{array}{l}\text { PCR product } \\
(\mu \mathrm{l})\end{array}$ & $\begin{array}{l}\text { Buffer } \\
(\mu l)\end{array}$ & $\begin{array}{l}\text { Reaction } \\
\text { temperature }\end{array}$ & $\begin{array}{l}\text { Reaction } \\
\text { time }\end{array}$ \\
\hline 35delG & $B s l \mathrm{I}$ & 12.5 & 1.7 & $55^{\circ} \mathrm{C}$ & $4 \mathrm{~h}$ \\
\hline 235delC & Apa $\mathrm{I}$ & 5 & 1 & $37^{\circ} \mathrm{C}$ & $4 \mathrm{~h}$ \\
\hline 299-300delAT & Hsp92II (5) & 5 & 2 & $37^{\circ} \mathrm{C}$ & $16 \mathrm{~h}$ \\
\hline
\end{tabular}

RFLP, Restriction fragment length polymorphism; PCR, polymerase chain reaction

Table 2. GJB2 mutations in Chinese probands with nonsyndromic hearing loss

\begin{tabular}{llccc}
\hline & & \multicolumn{2}{c}{ Deaf probands with mutations } & \\
\cline { 3 - 4 } Mutation & Effect & Homozygotes & Heterozygotes & $\begin{array}{l}\text { Allele frequency } \\
\text { among deaf probands }\end{array}$ \\
\hline 35delG & Frameshift & 0 & 1 & 0.002 \\
109G-A & V37I, missense & 0 & 1 & 0.002 \\
235delC & Frameshift & 27 & 13 & 0.16 \\
299-300delAT & Frameshift & 0 & 1 & 0.002 \\
All & & 27 & 16 & 0.166 \\
\hline
\end{tabular}


general Chinese population is as low as 1 in 200 controls, consistent with the high frequency of deafness resulting from mating among deaf people.

The present result indicates that the most frequent mutation in $G J B 2$ is $235 \mathrm{delC}$, which is found in 40 of 43 affected individuals with $G J B 2$-detectable mutations. It has also been found in the Japanese, Korean, and Mongolian populations (Abe et al. 2000; Fuse et al. 1999; Kudo et al. 2000; Park et al. 2000; A. Pandya and W.E. Nance unpublished). Therefore, mutation in GJB2 is an important contributor to recessively inherited NSHL in the Chinese population, as also shown in other ethnic groups (Cohn et al. 1999).

Another mutation, 299-300delAT, has also been reported, mainly in East Asians (Abe et al. 2000; Kudo et al. 2000; Park et al. 2000), although it does not appear to be common in any population yet studied. No second mutation in $G J B 2$ was detected from the proband and his mother with a heterozygous 299-300 delAT mutation, leading us to question whether this mutation was dominantly inherited. It is more likely that the apparently normal allele in both individuals in fact carried an inactivating mutation that escaped our analysis. Although dominant GJB2 mutations have been described, leading to DFNA3 hearing loss, these all produce a full-length but abnormal protein, which can probably exert a dominant negative effect. Numerous other chain-terminating mutations in GJB2 are known (http:// www.iro.es/deafness/). They typically act as null alleles, and heterozygotes have normal hearing.

Although numerous mutations of this gene occur that cause deafness, a single mutation, 35delG, predominates in Europe and the United States (Denoyelle et al. 1997; Gabriel et al. 2001; Gasparini et al. 1997; Green et al. 1999; Shahin et al. 2002). 35delG is absent in the Japanese (Abe et al. 2000; Fuse et al. 1999; Kudo et al. 2000) and rare in Koreans (Park et al. 2000). Our data show that the $35 \mathrm{delG}$ mutation is not common in the Chinese population, consistent with the case in other East Asians. GJB2 mutations are consistent with ethnic predilections.

Recent studies show a shared origin of the mutation in GJB2, such as the 167delT mutation in Ashkenazi Jews and the R143W mutation in several families in a Ghanaian village (Brobby et al. 1998; Morell et al. 1998). Haplotyping needs to be performed with $235 \mathrm{delC}$, the most prevalent mutation in Chinese and other East Asians, to evaluate the hypotheses relating to its origin.

These data support the use of screening programs in future, such as appropriate genetic tests, as a valuable complement to audiometric screens to identify neonates with heritable congenital hearing impairment in nonendogamous Chinese. Applying this test may facilitate earlier habilitation in a substantial percentage of deaf infants and ultimately provide parents with precise clinical diagnosis, appropriate prognostic genetic counseling, and proper medical management information.

Acknowledgments We thank all the families and patients for their cooperation in our study. We thank Dr. Pu Dingfang for technical support. This work was supported by grant 2000-A-10 from the Center for Human Disease Genomic, Peking University.

\section{References}

Abe S, Usami S, Shinkawa H, Kelley PM, Kimberling WJ (2000) Prevalent connexin 26 gene (GJB2) mutations in Japanese. J Med Genet 37:41-43

Brobby GW, Muller-Myhsok B, Horstmann RD (1998) Connexin 26 R143W mutation associated with recessive nonsyndromic sensorineural deafness in Africa. N Engl J Med 338:548-550

Cohn ES, Kelley PM (1999) Clinical phenotype and mutations in connexin 26 (DFNB1/GJB2), the most common cause of childhood hearing loss. Am J Med Genet 89:130-136

Denoyelle F, Weil D, Maw MA, Wilcox SA, Lench NJ, Allen-Powell DR, Osborn AH, Dahl HH, Middleton A, Houseman MJ, Dode C, Marlin S, Boulila-ElGaied A, Grati M, Ayadi H, BenArab S, Bitoun P, Lina-Granade G, Godet J, Mustapha M, Loiselet J, El-Zir E, Aubois A, Joannard A, Petit C (1997) Prelingual deafness: high prevalence of a $30 \mathrm{delG}$ mutation in the connexin 26 gene. Hum Mol Genet 6:2173-2177

Denoyelle F, Lina-Granade G, Plauchu H, Bruzzone R, Chaib H, LeviAcobas F, Weil D, Petit C (1998) Connexin 26 gene linked to a dominant deafness. Nature 393:319-320

Estivill X, Fortina P, Surrey S, Rabionet R, Melchionda S, D'Agruma L, Mansfield E, Rappaport E, Govea N, Mila M, Zelante L, Gasparini P (1998) Connexin-26 mutations in sporadic and inherited sensorineural deafness. Lancet 351:394-398

Fuse Y, Doi K, Hasegawa T, Sugii A, Hibino H, Kubo T (1999) Three novel connexin26 gene mutations in autosomal recessive nonsyndromic deafness. Neuroreport 10:1853-1857

Gabriel H, Kupsch P, Sudendey J, Winterhager E, Jahnke K, Lautermann J (2001) Mutations in the connexin26/GJB2 gene are the most common event in non-syndromic hearing loss among the German population. Hum Mutat 17:521-522

Gasparini P, Estivill X, Volpini V, Totaro A, Castellvi-Bel S, Govea N, Mila M, Della Monica M, Ventruto V, De Benedetto M, Stanziale P, Zelante L, Mansfield ES, Sandkuijl L, Surrey S, Fortina P (1997) Linkage of DFNB1 to nonsyndromic neurosensory autosomal recessive deafness in Mediterranean families. Eur J Hum Genet 5:83-88

Green GE, Scott DA, McDonald JM, Woodworth GG, Sheffield VC, Smith RJ (1999) Carrier rates in the midwestern United States for GJB2 mutation causing inherited deafness. JAMA 28:2211-2216

Kelley PM, Harris DJ, Comer BC, Askew JW, Fowler T, Smith SD, Kimberling WJ (1998) Novel mutations in the connexin 26 gene (GJB2) that cause autosomal recessive (DFNB1) hearing loss. Am J Hum Genet 62:792-799

Kelsell DP, Dunlop J, Stevens HP, Lench NJ, Liang JN, Parry G, Mueller RF, Leigh IM (1997) Cx26 mutation in hereditary nonsyndromic sensorineural deafness. Nature 387:80-83

Kudo T, Ikeda K, Kure S, Matsubara Y, Oshima T, Watanabe K, Kawase T, Narisawa K, Takasaka T (2000) Novel mutations in the connexin 26 gene $(G J B 2)$ responsible for childhood deafness in the Japanese population. J Med Genet 90:141-145

Morell RJ, Kim HJ, Hood LJ, Goforth L, Friderici K, Fisher R, Van Camp G, Berlin CI, Oddoux C, Ostrer H, Keats B, Friedman TB (1998) Mutations in the connexin 26 gene (GJB2) among Ashkenazi Jews with nonsyndromic recessive deafness. N Engl J Med 339:15001505

Park HJ, Hahn SH, Chun YM, Park K, Kim HN (2000) Connexin26 mutations associated with nonsyndromic hearing loss. Laryngoscope 110:1535-1538

Scott DA, Kraft ML (1998) Connexin mutation and hearing loss. Nature 391:32

Shahin H, Walsh T, Sobe T, Lynch E, King MC, Avraham KB, Kanaan M (2002) Genetics of congenital deafness in the Palestinian population: multiple connexin 26 alleles with shared origins in the Middle East. Hum Genet 110:284-289

Van Camp G, Smith RJ (2002) Connexin-deafness homepage. http://www.iro.es/deafness/

Zelante L, Gasparini P, Estivill X, Melchionda S, D'Agruma L, Govea N, Mila M, Monica MD, Lutfi J, Shohat M, Mansfield E, Delgrosso K, Rappaport E, Surrey S, Fortina P (1997) Cx26 mutation associated with the most common form of nonsyndromic nuerosensary autosomal recessive deafness (DFNB1) in Mediterranceans. Hum Mol Genet 6:1605-1609 